Calsbeek, H., Rijken, M., Bekkers, M.J.T.M., Berge Henegouwen, G.P. van, Dekker, J. Coping in adolescents and young adults with chronic digestive disorders: impact on school and leisure activities. Psychology \& Health: 2006, 21(4), 447-462

\begin{tabular}{|l|l|}
\hline Postprint Version & 1.0 \\
\hline Journal website & $\underline{\mathrm{http}: / / \text { www.informaworld.com/smpp/content?content=10.1080/14768320500410 }}$ \\
\hline Pubmed link & $\underline{\underline{910}}$ \\
\hline DOI & $10.1080 / 14768320500410910$ \\
\hline
\end{tabular}

This is a NIVEL certified Post Print, more info at http://www.nivel.eu

\title{
Coping in adolescents and young adults with chronic digestive disorders: Impact on school and leisure activities
}

\author{
HISKE CALSBEEK ${ }^{1}$, MIEKE RIJKEN ${ }^{1}$, MARC J. T. M. BEKKERS ${ }^{2}$, GERARD P. VAN BERGE \\ HENEGOUWEN $^{3}$, \& JOOST DEKKER ${ }^{4}$ \\ ${ }^{1}$ NIVEL, Netherlands Institute for Health Services Research, P.O. Box 1568, 3500 BN Utrecht, The \\ Netherlands, \\ ${ }^{2}$ PON Institute for Social Research and Development, P.O. Box 90123, 5000 LA Tilburg, The Netherlands, \\ ${ }^{3}$ Department of Gastroenterology, University Medical Centre Utrecht, P.O. Box 85500, 3508 GA Utrecht, \\ The Netherlands, \\ ${ }^{4}$ Department of Rehabilitation Medicine, VU University Medical Centre Amsterdam, P.O. Box 7057, 1007 \\ MB Amsterdam, The Netherlands (
}

\section{ABStract}

Coping strategies were compared across adolescents and young adults with several chronic digestive disorders and healthy peers, and across age groups. Subsequently, the impact of coping on performance in school and leisure activities was investigated.

Participants were adolescents and young adults (age 12 to 25 years) suffering from inflammatory bowel diseases (IBD), chronic liver diseases, congenital diseases, coeliac disease or food allergy (total $n=521$ ) and healthy controls $(n=274)$. For comparison reasons, a generic coping measuring instrument was employed: the shortened version of the Coping Inventory for Stressful Situations (CISS-21). The CISS-21 assesses three meta coping strategies: taskoriented, emotion-oriented and avoidance coping.

Comparisons between several groups only revealed less use of coping strategies in the youngest adolescents. No differences were found among diagnostic groups, nor between diagnostic groups and control group. Coping was found to be related to school and leisure activities of adolescents and young adults with chronic digestive disorders.

\section{INTRODUCTION}

Having a chronic disease can be considered a major life event regarding the initial shock of the diagnosis, or a sequence of daily hassles if one highlights the problems that a person has to deal with daily (Perrez \& Reicherts, 1992). In the literature, major life events and daily hassles have been identified as two types of stressors (Boekaerts \& Röder, 1999). Over the last few decades, the point of view on the impact of these stressors on the individual's functioning has been shifted from the assumption of a greater impact of major life events (e.g. parental divorce) to the insight that daily hassles (e.g. failing at school or feeling ill) can be more stressful (Boekaerts \& Ro“" der, 1999). Having a chronic digestive disorder can be easily considered a sequence of daily hassles: physical complaints, use of medication, disability in endurance and the need to diet adherence (Calsbeek, Rijken, Bekkers, Dekker, \& Van Berge Henegouwen, in press), are common aspects these patients have to deal with daily.

Most studies on coping with daily hassles use the transactional model of Lazarus and Folkman (1984) as a frame of reference (Boekaerts \& Ro“" der, 1999). Central to this model is that people who are confronted with a stressor evaluate this stressor and the availability of coping resources. Such individual appraisal 
Calsbeek, H., Rijken, M., Bekkers, M.J.T.M., Berge Henegouwen, G.P. van, Dekker, J. Coping in adolescents and young adults with chronic digestive disorders: impact on school and leisure activities. Psychology \& Health: 2006, 21(4), 447-462

determines the ability to adapt. The most widely cited and adopted definition of coping is the one derived from this model: constantly changing cognitive and behavioural efforts to manage specific external and/or internal demands that are appraised as taxing or exceeding the resources of the person.

Research on child-adolescent coping, however, is characterized by a lack of clarity and consensus in conceptualizing coping (Compas, Connor-Smith, Saltzman, Thomsen,\&Wadsworth, 2001). In addition to recent conceptualizations of coping more explicitly concerning childhood and adolescence, many studies are based on the adult coping model of Lazarus and Folkman (Compas et al., 2001). Consistent with this approach, we also adopted their definition of coping.

One might expect that adolescents and young adults with a chronic disease experience more stress than their peers. However, Boekaerts and Ro"der (1999) did not find any empirical study to support this expectation. In the authors' own study (Calsbeek et al., in press) it was found that, compared with healthy controls, adolescents and young adults with inflammatory bowel diseases (IBD), chronic liver diseases or food allergy reported more disease burden, including physical complaints, the need to diet adherence, disabilities in endurance and hospitalization. Moreover, with regard to social functioning, in particular, adolescents and young adults with chronic liver diseases or IBD reported more difficulties in school and leisure activities, compared with healthy peers (Calsbeek, Rijken, Bekkers, Kerssens, Dekker, \& Van Berge Henegouwen, 2002).

Several studies (Boekaerts \& Ro“der, 1999; Maes, Leventhal, \& De Ridder, 1996) show that controllable situations provoke more problem-focussed coping than avoidance, whereas less controllable or changeable situations are found to be more often handled with emotion-focussed coping or avoidance. Considering the nature of the daily consequences of several chronic digestive disorders, it can $448 \mathrm{H}$. Calsbeek et al. be hypothesized that having a controllable or uncontrollable chronic disease affects their way of handling general problems. For example, diseases like coeliac disease or food allergy can be considered predominantly controllable as both disorders can be controlled very well by following a diet: in case of coeliac disease a gluten-free diet has to be followed, whereas food allergy patients have to follow a diet in which the product causing the allergic reaction is left out. In general, when the prescribed diets are followed strictly, it is possible for patients to live a normal life. Thus, in particular, adolescents and young adults with these chronic digestive disorders can be expected to use task-oriented coping strategies more often than emotion-focussed or avoidance coping. On the other hand, IBD and chronic liver diseases can be considered less controllable by patients. IBD is regarded as a highly unpredictable disease, with unexpected exacerbations and remissions (Engstrom, 1999). Also, chronic liver diseases can be considered as very threatening: it is associated with a heavy morbidity, with the prospect or undergoing of a liver transplantation and with a more restrictive life expectation. Adolescents and young adults with IBD or a chronic liver disease can therefore be expected to use more emotion-focussed or avoidance coping strategies.

Furthermore, it is hypothesized that coping processes are responsive to changes in individuals as a result of biological, cognitive and social development (Compas et al., 2001). According to Compas et al. (2001), developmental changes may contribute to changes in coping responses. It therefore can be assumed that differences regarding the use of coping strategies exist between age groups.

Finally, in the literature on coping it is assumed that coping strategies play a part in the adaptation process of dealing with a chronic disease. In general, problem-focussed coping strategies have been found to be associated to better adjustment, whereas emotion-focussed coping strategies have been found to be related to poor adjustment (Kershaw, Northouse, Kritpracha, Schafenacker, \& Mood, 2004). Definitions of adjustment in coping studies, however, mostly concern psychological or physical health outcomes (Aldwin \& Yancura, in press; Maes et al., 1996). It is beyond question that health outcomes are important to chronically ill patients. Nevertheless, taking practical consequences into consideration, assessment of social outcomes in terms of everyday life measures may be more relevant (Maes et al., 1996).

Elaborating on the present research, we first wished to compare coping strategies in adolescents and young adults with several chronic digestive disorders and controls without chronic digestive disorders, and in various age groups. The second objective of this study was to determine whether performance in school and leisure activities of adolescents and young adults with chronic digestive disorders is (partly) dependent on the use of coping strategies. 
Calsbeek, H., Rijken, M., Bekkers, M.J.T.M., Berge Henegouwen, G.P. van, Dekker, J. Coping in adolescents and young adults with chronic digestive disorders: impact on school and leisure activities. Psychology \& Health: 2006, 21(4), 447-462

\section{METHODS}

\section{Study population}

Participants of research were adolescents and young adults aged between 12 and 25, suffering from chronic digestive diseases, categorized as IBD, chronic liver diseases, congenital disorders, food allergy and coeliac disease. Patients were recruited via 18 medical specialists in 9 academic and specialized hospitals using the following criteria: being diagnosed within one of the five diagnostic categories stated by a certified medical specialist, illness duration of at least six months, age from 12 to 25, being non-institutionalized, being aware of diagnosis, not being terminally ill, being mentally capable to participate and mastering the Dutch language sufficiently. Extra patients with coeliac disease were recruited through a patient organization, using the same criteria (diagnosis had to be confirmed by at least one small-bowel biopsy). There was no selection on illness activity or severity of complaints and disability.

Controls were randomly recruited from the patient files of 173 general practitioners, all being general practitioners of participating patients. In The Netherlands (almost) every inhabitant is registered with a general practitioner.

In recruiting controls, the same criteria were used as for the recruitment of patients, except being diagnosed within one of the five diagnostic categories.

General practitioners were provided with a random set of three different letters of the alphabet on the basis of which they were requested to select three controls with surnames starting with the indicated letters and fitting the specified criteria.

Informed consent The study was approved by all participating hospitals' ethical committees.

All participants gave written informed consent (if younger than 18 years, one of the parents or carers had to sign as well). Only after informed consent was received, a written questionnaire was sent to the respondents.

\section{Measurement}

Data were collected by a mailed questionnaire. Four background variables were measured: gender, age, socio-economic status and puberty status. Socioeconomic status was operationalized by the highest education of one of the parents or carers on a 7-point-scale, from (1) no education or only primary school to (7) a completed university training. Puberty status was assessed by physical characteristics: having had the first menstruation in case of female participants and the presence of a heavy voice in combination with axillary hair in male participants.

Puberty status was taken into account because of the assumption that chronic disorders can be accompanied with a delayed puberty (Sinnema, 1996), a factor that could play a role in school and leisure activities. Furthermore, eight burden of disease measures were assessed: physical complaints, anxiety, depression, disability in endurance, hospitalization, use of medication, the need to diet adherence and toilet use. Physical complaints were measured by a set of 23 complaints, based on literature and brochures of physicians and patients' associations. All items were scored on a 3-point-scale from (0) no trouble to (2) much trouble during the last four weeks. Anxiety and depression were measured by the Hospital Anxiety and Depression Scale (HADS) (Spinhoven et al., 1997; Zigmund \& Snaith, 1983), both consisting of 7 items (alphas $=0.79$ and 0.72 , respectively), and scored on a 4-point-scale.

Disability in endurance was assessed by a scale derived from the Children Quality Of Life questionnaire (TACQOL) (Verrips et al., 1998), consisting of 3 items (alpha=0.86). Hospitalization was measured by a scale consisting of 2 items: 'number of times hospital admission' and 'number of times undergoing surgery' (alpha=0.75). Daily use of medication was assessed by the number of times of medicine intake a day, at the moment of this study. The need to diet adherence was measured on a 4-point-scale, from (0) no diet at all ("I can eat and drink what I want") to (3) strict diet adherence. Finally, toilet use refers to going to the toilet at night because of bowel movement/defecation or stoma care.

This item was assessed on a 5-point-scale, ranging from (0) never to (4) always.

Coping was assessed by the shortened version of the Coping Inventory for Stressful Situations (CISS-21)

(De Ridder \& Van Heck, 2003; Endler \& Parker, 1999). The CISS is a theoretically derived, generic measuring instrument.

The CISS consists of 21 items measuring three coping strategies: emotionoriented coping (e.g. "Become very upset”), task-oriented coping (e.g. "Work to understand the situation'”) and avoidance coping (e.g. "Visit a friend").

Each scale consists of 7 items, randomly distributed within the form to control for order effects. 
The CISS has been frequently used in chronically ill patients with various diseases and has proven to have good psychometric characteristics in adult samples (as from 16 years) (Endler \& Parker, 1994).

Furthermore, confirmatory factor analyses provided evidence for a satisfactory fit and the invariance of the theoretically assumed three-factor structure of the CISS in adolescents and young adults in a younger target group (as from 12 years), with and without various chronic digestive disorders (Calsbeek, Rijken, Van Berge Henegouwen, \& Dekker, in press). As the factor loading of one item relating to avoidance coping “Take some time off and get away from the situation” appeared not to be significant in most of the samples, it was decided to exclude this item (Calsbeek et al., subm.), leaving the avoidance coping scale with 6 items instead of 7. In the so constructed scales, Cronbach's alphas were found to be 0.78 or higher, in diagnostic groups as well as in controls and in several age groups.

Respondents were asked to rate each item on a 5-point-scale ranging from (1) " not at all” to (5) "very much'”. Scale scores were transposed to the same format as the item scores (1-5).

Five aspects of school and leisure activities of adolescents and young adults were assessed (Calsbeek et al., 2002): school absenteeism due to illness, educational level, going out, undertaking cultural activities and friendship. Firstly, school absenteeism was measured by whole weeks absence during the total school period. Educational level was assessed by the highest educational level at the moment of this study, on a 7point-scale from (1) no education or only primary school to (7) university level. Going out and undertaking cultural activities were assessed by two scales derived from The Netherlands Health Interview Survey (Statistics Netherlands, 1999). The scale 'going out' consisted of 3 items: going to the movies, going to a disco or house party and visiting a pub (alpha=0.63). Undertaking cultural activities was assessed by 4 items: visiting a library, going to a play or concert, visiting a museum and reading books (alpha $=0.62$ ). These items were scored on a 4-point-scale. In order to facilitate interpretation, the scale scores were transposed to the same format (1-4). Finally, friendship was assessed by 2 items derived from the national survey Youth and Sex (Vogels \& van der Vliet, 1990): 'having friends' and 'undertaking activities with friends' (alpha=0.62). Again, as both items were scored on a 5-point-scale, the scale score was transposed to the same format to facilitate interpretation.

\section{STATISTICS}

To describe the sample, socio-demographic descriptives were computed, followed by analyses of variance or Chi-square tests to test differences between groups. In analysis of variance, Scheffe'-(homogeneous groups) or Tamhane's T2-(non-homogeneous groups) procedure was used.

In order to compare the use of coping strategies between adolescents and young adults with various chronic digestive disorders and controls (first research question), analysis of variance was applied. In this procedure age, gender, puberty status and socio-economic status were added as covariates to control their effects. These background variables appeared to differ significantly between groups (see results section), while being associated with most of the outcome measures.

The same procedure was followed in comparing the use of coping strategies in different age groups (12-14, 15-17, 18-20 and 21-24 years), except that in these analyses type of diagnosis was introduced as a covariate (instead of age).

In dividing the respondents into different age groups, we followed a commonly used classification, used in national publications (Statistics Netherlands: 12-17 and 18-24 years) and refined both groups further as we were interested in possible shifts in coping.

To investigate the relationship between coping and school and leisure activities in patients (second research question), two statistical procedures were performed.

First, Pearson correlation coefficients were computed between coping strategies and aspects of school and leisure activities in the patients group. Second, multiple regression analyses were performed on each aspect of school and leisure activities.

These regression analyses were carried out in three steps. In the first step, background variables were entered into the regression equation (age as a continuous variable, gender and socio-economic status), inclusive of type of diagnosis (four diagnostic groups as dummies, with one diagnostic group as reference group); in the second step eight disease burden indices were entered, and in the final step, the three coping strategies were entered into the model. 
Calsbeek, H., Rijken, M., Bekkers, M.J.T.M., Berge Henegouwen, G.P. van, Dekker, J. Coping in adolescents and young adults with chronic digestive disorders: impact on school and leisure activities. Psychology \& Health: 2006, 21(4), 447-462

\section{RESULTS}

\section{Sample}

A total of 521 adolescents and young adults suffering either from IBD ( $\mathrm{n}=190)$, chronic liver diseases $(\mathrm{n}=51)$, congenital digestive disorders $(\mathrm{n}=122)$, coeliac disease $(\mathrm{n}=61)$ or food allergy $(\mathrm{n}=97)$ adequately completed the questionnaire.

Mean response was $50.3 \%$ varying from $38.6 \%$ in adolescents and young adults with chronic liver diseases to $58.8 \%$ in participants with IBD. The sample also included 274 controls, response rate $49.0 \%$. The characteristics of the sample are summarized in Table I. The mean age in the different groups varied from 18.4 to 22.1 years, the IBD and chronic liver disease groups being significantly older than the control group and the other three diagnostic groups. The percentage female participants varied from 45.9 to $70.1 \%$ in the various groups, the food allergy group consisted of significantly more female respondents than the control group. In addition, differences were found among the diagnostic groups as well. The mean score on socioeconomic status varied from 3.8 to 4.7. Although analysis of variance showed an overall statistic indicating significant differences between groups, the post hoc test (Scheffe) did not reveal any differences, probably due to small numbers in subgroups. Finally, the percentage participants that had not reached puberty status varied from 5.4 to $16.8 \%$, being significantly lower in the IBD group than in the control group and in the congenital disorders group.

\section{Use of coping strategies}

Table II(a) presents mean scores on the three coping strategies in diagnostic groups and control group. Results show highest scores on task-oriented coping and lowest scores on emotion-oriented coping. No significant differences were found between adolescents and young adults with various chronic digestive disorders and healthy controls, nor among the diagnostic groups. Apparently, adolescents and young adults in the different diagnostic groups and healthy peers use task-oriented coping strategies, emotion-oriented coping strategies and avoidance coping to the same extent.

\section{[TABLE1]}

\section{[TABLE 2A]}

\section{[TABLE 2B]}

\section{[TABLE 3]}

When several age groups are distinguished, differences in the use of coping strategies come to light. In Table II(b) mean scores on the coping strategies are given for four age groups. Analyses of variance showed significant differences between age groups. In the youngest group (12-14 years) significantly lower scores were found compared with the older groups on all dimensions of coping.

Furthermore, adolescents in the age of 15-17 years scored significantly lower on task-oriented coping than older age groups. Adolescents in the two oldest categories were found to use coping strategies to the same extent.

\section{Relation between coping and school and leisure activities}

First, correlation coefficients were computed to investigate the relation between coping and school and leisure activities of patients. In Table III Pearson correlation coefficients are presented. In general, weak but significant correlations were found between all school and leisure aspects on the one hand and one or two coping strategies on the other hand. School absenteeism, educational level and going out correlated positively with task-oriented coping. Furthermore, going out appeared to be positively correlated with avoidance coping. Avoidance coping was also positively associated with both cultural activities and friendship. Only one negative association was found: between friendship and emotion-oriented coping. Secondly, regression analyses of the five school and leisure aspects were performed on coping strategies, with background characteristics and burden of disease indices also being part of the regression model, entered in separate steps. Results of these analyses are shown in Table IV. From this table it can be 
Calsbeek, H., Rijken, M., Bekkers, M.J.T.M., Berge Henegouwen, G.P. van, Dekker, J. Coping in adolescents and young adults with chronic digestive disorders: impact on school and leisure activities. Psychology \& Health: 2006, 21(4), 447-462

concluded that generic coping resources contribute significantly to the regression models on educational level, going out and friendship, but not on school absenteeism and leisure activities.

Regarding educational level, the total model explained $20 \%$ of the variance $(F=5.969, d f=19,353, p<$ 0.001), of which background characteristics provided the largest contribution, especially by socio-economic status (operationalized by the educational level of the parents), and - obviously - age and puberty status. Burden of disease also provided a significant contribution to the model, with physical complaints (in a positive way) and toilet use (negative) as important factors. Apart from these factors, coping appeared to explain a significant part of the variance as well, with task-oriented coping significantly related to a higher educational level.

With respect to going out, the final model explained $13 \%$ of the variance $(F=4.216, d f=19,379, p<0.001)$, the largest part being explained by coping.

\section{[TABLE 4]}

Avoidance coping appeared to be a positive predictor of going out. Again, background characteristics (age) and burden of disease (disability in endurance) also provided significant contributions.

Finally, with regard to friendship, $17 \%$ of the variance was explained by the final regression model $(\mathrm{F}=5.402, \mathrm{df}=19,378, \mathrm{p}<0.001)$, again with the largest part being explained by coping. Two coping strategies were identified as significant contributors: avoidance coping in a positive way and emotionoriented coping in a negative way. Next to coping, burden of disease explained a significant part of the variance, with disability in endurance and toilet use as important (negative) factors.

\section{DISCUSSION}

The first objective of this study was to compare coping strategies between different diagnostic and age samples: between adolescents and young adults with various chronic digestive disorders and healthy peers, among diagnostic groups, and among several age groups. Contrary to our hypotheses, no differences were found between the several diagnostic groups nor between the diagnostic groups and the control group. Therefore, it can be stated that adolescents and young adults with several chronic digestive disorders and healthy peers handle general problems or stressful situations in the same way. These findings support previous results of studies in adolescents with other chronic diseases, such as diabetes, rheumatic diseases and asthma (Boekaerts and Ro“ der, 1999). There may be a difference, however, between generic coping (as measured in our study) and disease-specific coping, i.e. coping specifically aimed at the disease and disease burden. Whereas, apparently, no differences exist among diagnostic groups as far as generic coping is concerned, adolescents and young adults with various chronic digestive disorders possibly differ in the use of disease-specific coping strategies.

Making a distinction between age groups, our results indicate that adolescents in the age of 12 to 14 years, generally make less use of coping strategies than older adolescents. Compared with older age groups, these youngsters were found to report lower scores on each coping strategy. Moreover, on the scale for taskoriented coping, adolescents in the age of 15 to 17 years also appeared to report lower scores compared with older age groups. These findings suggest that, although task-oriented coping strategies were found to be the most frequently reported strategies in handling stressful situations, this way of coping requires certain skills which need to be developed. In addition, it is likely that skills in order to use strategies relating to avoidance coping and emotion-oriented coping are developed in an earlier stage. It is assumed (Compas et al., 2001) that more complex methods of coping efforts emerge in early to middle childhood, with the development of more language and metacognitive capacities such as cognitive reframing or restructuring a problem situation. Greater diversity and flexibility in the range of coping responses available to the individual is expected to develop during middle childhood and adolescence. Results of our study can be considered consistent with this expectation.

With regard to the second research question, to determine whether performance in school and leisure activities of young patients with chronic digestive disorders is dependent on generic coping resources, results indicate that coping can be considered a predictor for some aspects. Even when background characteristics, type of diagnosis and disease burden measures are taken into consideration, some coping strategies were identified as predictors, especially with regard to educational level, going out and friendship. 
Calsbeek, H., Rijken, M., Bekkers, M.J.T.M., Berge Henegouwen, G.P. van, Dekker, J. Coping in adolescents and young adults with chronic digestive disorders: impact on school and leisure activities. Psychology \& Health: 2006, 21(4), 447-462

Regarding educational level, task-oriented coping was found to relate significantly with a higher educational level. This coping strategy is aimed at solving the problem, cognitively restructuring the problem or attempts to alter the situation. Obviously, using this kind of coping efforts is positively related to educational level.

Going out on the other hand appeared to be positively associated with avoidance coping. Making use of this kind of coping reaction, apparently is related with more going out in adolescents and young adults with chronic digestive diseases. Avoidance coping was also found to be a positive predictor on friendship. In other words, handling problems and stressful situations by activities and cognitive changes aimed at avoiding the stressful situation via distracting oneself with other situations or tasks or via social diversion can be considered a positive predictor for the number of friends, undertaking activities with friends and going out. It must be noted that the scale avoidance includes two sub-dimensions, namely person-oriented (social diversion) and task-oriented (distraction) coping strategies (Endler \& Parker, 1990). The items which relate to person oriented coping strategies ("Visit a friend"', "Spend time with a special person", and "Phone a friend") involve behaviour directed to a friend or a special person. However, repeated analyses without these items, thus only including three items relating to distraction (alpha=0.84), did not change the relationships with going out and friendship (data not shown).

Thirdly, emotion-oriented coping appeared to be negatively related to friendship.

Emotion-oriented coping refers to emotional reactions that are self-oriented and aims to reduce stress. Reactions include emotional responses, selfpreoccupation and fantasizing (Endler \& Parker, 1999). Probably, self-oriented coping efforts leave less room for sharing problems with friends. In the present study, however, a cross-sectional design was used, so that no statements on the direction of an association can be made. As a consequence, it is also possible that having no friends or only a few friends results in using predominantly selforiented coping strategies in handling stressful situations.

Finally, school absenteeism and undertaking cultural activities did not appear to be (partly) dependent on the use of coping strategies. Regression analyses revealed that, in case of school absenteeism, burden of disease explained the largest part of the variance, in particular disability in endurance, medical treatment and medicine use. Regarding cultural activities, background characteristics, especially gender and socioeconomic status, appeared to explain the largest part of the variance. Apparently, school absenteeism and undertaking cultural activities are not so much dependent on the use of coping strategies as on burden of disease measures or background characteristics.

According to Compas et al. (2001), there is evidence from more than 60 studies suggesting that coping matters in the psychological adjustment of adolescents exposed to stressors. In general, problem-focussed and active coping (i.e. taskfocussed coping) have been found to be associated with better adjustment, whereas emotion-focussed coping and passive coping (avoidance, emotionfocussed coping strategies) have been found to be related to poorer adjustment (Compas et al., 2001; Kliewer, 1997; Maes et al., 1996). However, most studies operationalize adjustment in terms of psychological outcomes. Positive effects on psychological adjustment are not necessarily parallel to beneficial effects concerning medical and social outcomes like compliance, the use of medical resources or work absenteeism (Maes et al., 1996). With regard to task-focussed and emotionfocussed coping strategies, our results - relating to social outcomes are consistent with previously found associations. With regard to avoidance coping, our results suggest a positive association with social outcomes such as going out and friendship.

In general, in addition to our research questions, highest scores were found on task-oriented coping and lowest scores on emotion-oriented coping. In other words, coping reactions referring to solving the problem, cognitively restructuring the problem or attempts to alter the situation were the most frequently reported coping efforts in our study. In the literature on adolescent coping, due to various coping measurement techniques, a rich variety of coping responses have been reported. This makes it difficult to compare results (Boekaerts, 1996). In studies on adult coping, similar outcomes have been reported (Heymans \& Rijken, subm.).

In interpreting these findings, it should be noted that using a generic measuring instrument, the assumption is being made that there is some consistency in adolescent use of coping strategies across stressful situations. According to Ayers, Sandler and Twohey (1998), several studies have provided evidence that this assumption is quite reasonable for adolescents.

In addition, we used a coping measuring instrument, the CISS, which was originally developed for use in adults. Although the underlying factor structure was the same when applied to a younger target group 
Calsbeek, H., Rijken, M., Bekkers, M.J.T.M., Berge Henegouwen, G.P. van, Dekker, J. Coping in adolescents and young adults with chronic digestive disorders: impact on school and leisure activities. Psychology \& Health: 2006, 21(4), 447-462

(Calsbeek et al., in press), the possibility exists that such an instrument may not adequately cover the full range of coping efforts used by adolescents and young adults (Ayers et al., 1998). However, although individual items of the CISS refer to coping behaviour, the underlying structure of the CISS assesses meta coping strategies which makes it improbable that coping efforts of adolescents are not covered.

Furthermore, due to the cross-sectional design of our study, no statements can be made on the (causal) role of coping; findings only concern associations between coping and the social position of adolescents and young adults with chronic digestive disorders.

A final point of attention involves the response of the research group, $50.3 \%$ in patients and $49.0 \%$ in controls. It appeared that in patients, respondents were on the average a half year younger than nonrespondents (respectively 19.6 and 20.1 years), and a higher percentage was female (respectively 57 and $49 \%$ females). The same pattern existed in the control group: the mean age in the respondents group was 18.5 years, compared with 20 years in non-respondents and $56 \%$ of the respondents was female in relation to $42 \%$ in the non-respondents group. In addition, to verify whether the control group was representative for the Dutch population between the ages of 12 and 25, data regarding educational level, failing classes and relationships were compared with national statistics (data not shown). With regard to these aspects, our controls were practically similar to the national statistics. In consequence, given a small deviation with regard to age and gender, the findings in our study can be considered rather representative.

Taking these considerations into account, it can be concluded that, apart from the impact of disease burden, coping is related to school and leisure activities of adolescents and young adults with chronic digestive disorders. Comparisons between several diagnostic and age groups only revealed differences between age groups, showing less use of all measured coping strategies in the youngest adolescents, in particular with regard to task-focussed coping. Positive contributions of task-oriented coping were found on educational level, and of avoidance coping on going out and friendship, while emotion-oriented coping related negatively to friendship.

Further research is needed to investigate the mechanisms through which coping is related to social outcome measures (mediating role) in adolescents and young adults with chronic digestive disorders. More detailed insight in such mechanisms can be helpful in preventing adolescents and young adults with chronic digestive disorders from difficulties in school and leisure activities.

\section{ACKNOWLEDGEMENTS}

This study was supported by a grant from the Foundation for Children's Welfare Stamps, Netherlands.

\section{REFERENCES}

Aldwin, C. M., \& Yancura, L. A. (in press). A comparison of the stress and trauma literatures. In P. P. Schnurr \& B. L. Green (Eds), Physical health consequences of exposure to extreme stress. Washington, DC: American Psychological Association.

Ayers, T. S., Sandler, I. N., \& Twohey, J. L. (1998). Conceptualization and measurement of coping in children and adolescents. In T. H. Ollendick \& R. J. Prinz (Eds), Advances in clinical child psychology (Vol. 20). New York: Plenum Press. Boekaerts, M. (1996). Coping with stress in childhood and adolescence. In M. Zeidler \& N. S. Endler (Eds), Handbook of coping. New York: John Wiley \& Sons. Boekaerts, M., \& Ro"der, I. (1999). Stress, coping and adjustment in children with a chronic disease: A review of the literature. Disability and Rehabilitation, 21, 311-337.

Calsbeek, H., Rijken, P. M., Bekkers, J. T.M., Kerssens, J. J., Dekker, J., \& Van Berge Henegouwen, G. P. (2002). Social position of adolescents with chronic digestive disorders. European Journal of Gastroenterology \& Hepatology, 14, 543-549.

Calsbeek, H., Rijken, P. M., Bekkers, J. T. M., Dekker, J., \& Van Berge Henegouwen, G. P. (in press). School and leisure activities in children and adolescents with chronic digestive disorders: Impact of disease burden. International Journal of Behavioral Medicine.

Calsbeek, H., Rijken, P. M., Van Berge Henegouwen, G. P., \& Dekker, J. (in press). Factor structure of the Coping Inventory for Stressful Situations (CISS-21) in adolescents and young adults with chronic digestive disorders.

Compas, B. E., Connor-Smith, J. K., Saltzman, H., Thomsen, A. H., \& Wadsworth, M. E. (2001).

Coping with stress during childhood and adolescence: Problems, progress and potential in theory and research. Psychological Bulletin, 127(1), 87-127.

De Ridder, D. T. D., \& Van Heck, G. L. (2003). Dutch version of the CISS. Lisse: Swets \& Zeitlinger (Swets Test Publishers). 
Calsbeek, H., Rijken, M., Bekkers, M.J.T.M., Berge Henegouwen, G.P. van, Dekker, J. Coping in adolescents and young adults with chronic digestive disorders: impact on school and leisure activities. Psychology \& Health: 2006, 21(4), 447-462

Endler, N. S., \& Parker, J. D. A. (1990). The multidimensional assessment of coping: A critical evaluation. Journal of Personality and Social Psychology, 58, 844-855.

Endler, N. S., \& Parker, J. D. A. (1994). Assessment of multidimensional coping: Task, emotion and avoidance strategies. Psychological Assessment, 1, 50-60.

Endler, N. S., \& Parker, J. D. A. (1999). Coping Inventory for Stressful Situations (CISS): Manual (second edition). Toronto: Multi Health Systems.

Engstrom, I. (1999). Inflammatory bowel disease in children and adolescents: Mental health and family functioning. Journal of Pediatric Gastroenterology and Nutrition, 28, s28-s33.

Heymans, M., \& Rijken, P. M. Self-management activities of asthma and COPD patients and their role in quality of life. Manuscript submitted for publication.

Kershaw, T., Northouse, L., Kritpracha, C., Schafenacker, A., \& Mood, D. (2004). Coping strategies and quality of life in women with advanced breast cancer and their family caregivers.

Psychology and Health, 19, 139-155.

Kliewer, W. (1997). Coping with chronic illness. In S. A. Wolchik \& I. N. Sandler (Eds), Handbook of children's coping. Linking theory and Interventions. New York: Plenum Press.

Lazarus, R. S., \& Folkman, S. (1984). Stress, appraisal and coping. New York: Springer.

Maes, S., Leventhal, H., \& De Ridder, D. T. D. (1996). Coping with chronic diseases. In M. Zeidler \& N. S. Endler (Eds), Handbook of coping. Theory, research, application. New York: Wiley.

Perrez, M., \& Reicherts, M. (1992). Stress, coping and health: a situation-behavior approach, theory, methods, applications. Seattle: Hogrefe \& Huber.

Sinnema G. (1996). De ontwikkeling van chronisch zieke adolescenten. [The development of chronically ill adolescents.] In J. D. Bosch, H. A. Bosma, D. N. Oudshoorn, J. Rispens, \& A. Vyt (Eds), Jaarboek Ontwikkelingspsychology, orthopedagogiek en kinderpsychiatrie. Houten/ Diegem: Bohn Stafleu Van Lochum.

Statistics Netherlands (CBS) (1999). Jeugd 1999. Cijfers en feiten [Youth 1999. Figures and facts.]. Voorburg/Heerlen: CBS.

Spinhoven, P., Ormel, J., Sloekers, P. P. H., Kempen, G. I. J. M., Speckens, A. E. M., \& Van Hemert, A. M. (1997). A validation study of the Hospital Anxiety and Depression Scale (HADS) in different groups of Dutch subjects. Psychological Medicine, 27, 363-370.

Verrips, G. H., Vogels, A. G. C., Verloove-Vanhorick, S. P., Fekkes, M., Koopman, H. M., Kamphuis R. P., et al. (1998). Health-related quality of life measure for children - the TACQOL. Journal of Applied Therapeutics, 1/4, 357-360.

Vogels, T., \& van der Vliet, R. (1990). Jeugd en seks. Gedrag en gezondheidsrisico's bij scholieren [Youth and sex. Behaviour and health risks in pupils.]. Den Haag: SDU.

Zigmund, A. S., \& Snaith, R. P. (1983). The Hospital Anxiety and Depression Scale.

Acta Psychiatrica Scandinavia, 67, 361-370.

462 H. Calsbeek et al. 
Table I. Characteristics of the diagnostic group and control groups.

\begin{tabular}{|c|c|c|c|c|c|c|c|}
\hline & $\begin{array}{c}\mathrm{I} \\
\mathrm{IBD} \\
(n=190)\end{array}$ & $\begin{array}{c}\text { II } \\
\text { Chronic liver } \\
\text { diseases } \\
(n=51)\end{array}$ & $\begin{array}{c}\text { III } \\
\text { Congenital } \\
\text { disorders } \\
(n=122)\end{array}$ & $\begin{array}{c}\text { IV } \\
\text { Coeliac } \\
\text { disease } \\
(n=61)\end{array}$ & $\begin{array}{c}\mathrm{V} \\
\text { Food } \\
\text { allergy } \\
(n=97)\end{array}$ & $\begin{array}{l}\text { Control } \\
\text { group } \\
(n=274)\end{array}$ & \\
\hline Age (mean, SD) & $22.1(2.3)^{\star} \#$ III, IV, V & $22.0(2.7)^{\star} \# \mathrm{III}, \mathrm{IV}, \mathrm{V}$ & 18.4 (3.7)\# I, II & 18.4 (3.7)\# I, II & 18.4 (3.8)\# I, II & 18.5 & $F(5)=38.21, p<0.001$ \\
\hline$\% 12-14$ & 0.5 & 2.0 & 21.3 & 18.0 & 21.6 & 17.9 & \\
\hline$\% 15-17$ & 4.2 & 3.9 & 18.0 & 21.3 & 17.5 & 26.6 & \\
\hline$\% 18-20$ & 17.4 & 23.5 & 24.6 & 23.0 & 27.8 & 19.0 & \\
\hline$\% 21-24$ & 77.9 & 70.6 & 36.1 & 37.7 & 33.0 & 36.5 & \\
\hline Gender (\% women) & 58.9 \# III & $51.0 \# \mathrm{~V}$ & 45.9 \# I, IV, V & $67.2 \#$ III & $70.1^{\star} \# \mathrm{II}, \mathrm{III}$ & 55.5 & $\mathrm{Chi}^{2}(5)=16.84, p=0.005$ \\
\hline $\begin{array}{l}\text { Socio-economic status } \\
\text { (Mean, SD) }\end{array}$ & $4.2(1.7)$ & $3.8(2.0)$ & $4.3(1.7)$ & $4.7(1.6)$ & $4.6(1.6)$ & $4.5(1.6)$ & $F(5)=2.78, p=0.017$ \\
\hline Puberty (\% reached) & $94.6^{\star} \# \mathrm{III}$ & 91.8 & 83.2 \# I & 93.3 & 90.7 & 89.0 & $\mathrm{Chi}^{2}(5)=11.98, p=0.035$ \\
\hline
\end{tabular}

${ }^{\star} p \leq 0.05$ in comparison with control group. $\# p \leq 0.05$ in comparison with indicated diagnostic group.

Table II(a). Mean scores (standard deviation) on 3 coping scales of the CISS in diagnostic groups and control group ${ }^{1}$

\begin{tabular}{|c|c|c|c|c|c|c|c|}
\hline & $\begin{array}{c}\text { IBD } \\
(n=190)\end{array}$ & $\begin{array}{l}\text { Chronic liver disease } \\
\quad(n=51)\end{array}$ & $\begin{array}{c}\text { Congenital disorders } \\
\quad(n=122)\end{array}$ & $\begin{array}{l}\text { Coeliac disease } \\
\quad(n=61)\end{array}$ & $\begin{array}{l}\text { Food allergy } \\
\quad(n=97)\end{array}$ & $\begin{array}{l}\text { Controls } \\
(n=274)\end{array}$ & \\
\hline Emotion-oriented coping (1-5) & $2.6(0.9)$ & $2.9(1.0)$ & $2.5(0.8)$ & $2.7(0.9)$ & $2.6(0.9)$ & $2.5(0.8)$ & $\begin{array}{l}F(5)=1.33, p=0.250 \\
\quad \text { between diagnostic groups: } \\
F(4)=1.43, p=0.224\end{array}$ \\
\hline Task-oriented coping (1-5) & $3.5(0.7)$ & $3.3(0.7)$ & $3.1(0.8)$ & $3.2(0.9)$ & $3.2(0.8)$ & $3.3(0.8)$ & $\begin{array}{l}F(5)=1.52, p=0.183 \\
\quad \text { between diagnostic groups: } \\
F(4)=1.33, p=0.259\end{array}$ \\
\hline Avoidance (1-5) & $3.2(1.0)$ & $3.1(0.9)$ & $3.0(1.0)$ & $3.0(0.9)$ & $3.1(1.0)$ & $3.0(0.9)$ & $\begin{array}{l}F(5)=0.52, p=0.763 \\
\quad \text { between diagnostic groups: } \\
F(4)=0.25, p=0.913\end{array}$ \\
\hline
\end{tabular}

${ }^{1}$ Differences in age, gender, socio-economic status and puberty status were being controlled in analyses of variance. 
Calsbeek, H., Rijken, M., Bekkers, M.J.T.M., Berge Henegouwen, G.P. van, Dekker, J. Coping in adolescents and young adults with chronic digestive disorders: impact on school and leisure activities. Psychology \& Health: 2006, 21(4), 447-462

Table II(b). Mean scores (standard deviation) on 3 coping scales of the CISS in four age groups.

\begin{tabular}{|c|c|c|c|c|c|}
\hline & $\begin{array}{c}\mathrm{I} \\
12-14 \\
(n=109)\end{array}$ & $\begin{array}{c}\mathrm{II} \\
15-17 \\
(n=135)\end{array}$ & $\begin{array}{c}\text { III } \\
18-20 \\
(n=168)\end{array}$ & $\begin{array}{c}\text { IV } \\
21-24 \\
(n=383)\end{array}$ & \\
\hline $\begin{array}{l}\text { Emotion-oriented } \\
\text { coping }(1-5)\end{array}$ & $2.2(0.8)^{\star} \mathrm{II}, \mathrm{III}, \mathrm{IV}$ & $2.5(0.8)^{\star} \mathrm{I}$ & $2.7(0.9)^{\star} \mathrm{I}$ & $2.7(0.9)^{\star} \mathrm{I}$ & $\begin{array}{c}F(3)=6.47 \\
p<0.001\end{array}$ \\
\hline $\begin{array}{l}\text { Task-oriented } \\
\text { coping }(1-5)\end{array}$ & $2.8(0.8)^{\star} \mathrm{II}, \mathrm{III}, \mathrm{IV}$ & $3.1(0.8)^{\star} \mathrm{I}, \mathrm{III}, \mathrm{IV}$ & $3.4(0.7)^{\star} \mathrm{I}, \mathrm{II}$ & $3.4(0.7)^{\star} \mathrm{I}, \mathrm{II}$ & $\begin{array}{c}F(3)=16.06, \\
p<0.001\end{array}$ \\
\hline $\begin{array}{l}\text { Avoidance } \\
\text { coping (1-5) }\end{array}$ & $2.6(1.0)^{\star} \mathrm{III}, \mathrm{IV}$ & $3.0(0.9)$ & $3.1(0.9)^{\star} \mathrm{I}$ & $3.1(0.9)^{\star} \mathrm{I}$ & $\begin{array}{r}F(3)=3.19 \\
p=0.023\end{array}$ \\
\hline
\end{tabular}

${ }^{\star} p \leq 0.01$ in comparison with indicated age group (after controlling for differences in gender, diagnosis, socio-economic status and puberty).

Table III. Correlation between coping scales and school and leisure measures, in patients with chronic digestive disorders $(n=521)$.

\begin{tabular}{lccccc}
\hline & School absenteeism & Educational level & Going out & Cultural activities & Friendship \\
\hline Emotion-oriented coping & -0.003 & 0.015 & -0.038 & 0.014 & $-0.220^{\star \star}$ \\
Task-oriented coping & $0.120^{\star \star}$ & $0.232^{\star \star}$ & $0.115^{\star \star}$ & 0.027 & 0.087 \\
Avoidance coping & 0.014 & 0.057 & $0.286^{\star \star}$ & $0.091^{\star}$ & $0.186^{\star \star}$ \\
\hline
\end{tabular}

Note: Pearson correlation coefficients.

${ }^{\star} p \leq 0.05 ;{ }^{\star \star} p \leq 0.01$. 
Table IV. Parameters of regression analyses (final betas) of school and leisure aspects on coping, in patients with chronic digestive disorders $(n=521)$.

\begin{tabular}{|c|c|c|c|c|c|c|c|c|c|c|c|c|c|c|c|}
\hline & \multicolumn{3}{|c|}{ School absenteeism } & \multicolumn{3}{|c|}{ Educational level } & \multicolumn{3}{|c|}{ Going out } & \multicolumn{3}{|c|}{ Cultural activities } & \multicolumn{3}{|c|}{ Friendship } \\
\hline & B & $\mathrm{AR}^{2}$ & $\Delta p$ & $\beta$ & $\mathrm{AR}^{2}$ & $\Delta p$ & $B$ & $\mathrm{AR}^{2}$ & $\Delta p$ & $B$ & $\mathrm{AR}^{2}$ & $\Delta p$ & $\beta$ & $\mathrm{AR}^{2}$ & $\Delta p$ \\
\hline Background characteristics: & & 0.047 & $\star \star$ & & 133 & $\star \star$ & & 0.032 & $\star \star$ & & 0.131 & $\star \star$ & & -0.005 & ns \\
\hline Age & -0.043 & & & $0.153^{\star}$ & & & $0.178^{\star \star}$ & & & -0.112 & & & -0.066 & & \\
\hline Gender & 0.063 & & & 0.033 & & & -0.086 & & & $0.244^{\star \star}$ & & & -0.065 & & \\
\hline Socio-economic status & 0.052 & & & $0.288^{\star \star}$ & & & 0.053 & & & $0.243^{\star \star}$ & & & 0.050 & & \\
\hline Puberty status & $0.105^{\star}$ & & & $0.125^{\star}$ & & & 0.051 & & & -0.034 & & & 0.070 & & \\
\hline $\mathrm{IBD}^{1}$ & 0.141 & & & 0.017 & & & 0.107 & & & -0.040 & & & 0.128 & & \\
\hline Chronic liver disease $^{1}$ & 0.064 & & & 0.062 & & & 0.046 & & & 0.068 & & & 0.117 & & \\
\hline Congenital digestive disorder ${ }^{1}$ & -0.060 & & & 0.012 & & & 0.099 & & & 0.097 & & & 0.078 & & \\
\hline Food allergy ${ }^{1}$ & -0.006 & & & 0.059 & & & -0.055 & & & 0.063 & & & -0.046 & & \\
\hline Burden of disease measures: & & 0.217 & $\star \star$ & & 0.186 & $\star \star$ & & 0.053 & * & & 0.147 & ns & & 0.077 & $\star \star$ \\
\hline Physical complaints & 0.096 & & & $0.129^{\star}$ & & & 0.079 & & & $0.145^{\star}$ & & & 0.037 & & \\
\hline Anxiety & 0.010 & & & -0.104 & & & 0.070 & & & -0.035 & & & 0.060 & & \\
\hline Depression & -0.111 & & & -0.122 & & & -0.094 & & & $-0.171^{\star \star}$ & & & -0.102 & & \\
\hline Disability in endurance & $0.151^{\star \star}$ & & & -0.054 & & & $-0.135^{\star}$ & & & 0.003 & & & $-0.157^{\star \star}$ & & \\
\hline Medical treatment & $0.329^{\star \star}$ & & & -0.079 & & & -0.013 & & & 0.007 & & & -0.088 & & \\
\hline Medicine use & $0.136^{\star}$ & & & -0.094 & & & -0.031 & & & 0.078 & & & -0.039 & & \\
\hline Diet & 0.104 & & & 0.003 & & & 0.110 & & & -0.053 & & & 0.086 & & \\
\hline Toilet use & -0.077 & & & $-0.129^{\star}$ & & & -0.034 & & & -0.033 & & & $-0.102^{\star}$ & & \\
\hline Coping scales: & & 0.216 & ns & & 0.202 & * & & 0.133 & $\star \star$ & & 0.143 & ns & & 0.174 & $\star \star$ \\
\hline Emotion-oriented & -0.042 & & & 0.060 & & & -0.070 & & & 0.058 & & & $-0.215^{\star \star}$ & & \\
\hline Task-oriented & 0.077 & & & $0.147^{\star \star}$ & & & -0.085 & & & 0.027 & & & -0.023 & & \\
\hline Avoidance & -0.010 & & & -0.009 & & & $0.331^{\star \star}$ & & & -0.005 & & & $0.319^{\star \star}$ & & \\
\hline
\end{tabular}

$\Delta p=$ change in significance level.

${ }^{1}$ Coeliac disease is reference group.

${ }^{\star} p \leq 0.05 ;{ }^{\star \star} p \leq 0.01$ 